\title{
Cachaças de Paraty. A patrimonialização de uma tradição
}

\author{
Nathália Caroline Dias \\ Mestra em Ciências Sociais \\ Universidade Federal de Juiz de Fora
}

Resumo: A cachaça, bebida alcoólica historicamente de origem brasileira, tem passado por profundas transformações materiais e simbólicas. Nesse sentido, pretendo analisar as transformações pelas quais as cachaças produzidas na cidade de Paraty (RJ) têm passado, particularmente, na última década, apresentando os resultados de trabalho de campo e entrevistas semiestruturadas realizados com os produtores e trabalhadores que lidam diretamente com a cachaça na cidade. A partir das teorias acerca dos patrimônios culturais, parto do pressuposto de que as cachaças de Paraty se caracterizam como um patrimônio cultural da cidade, apesar de oficialmente não o ser. Pois, os alambiques reunidos na Associação de Produtores e Amigos da Cachaça de Paraty possuem o certificado do governo federal de "Indicação de Procedência", o que lhes certificam a "tradição" na produção da cachaça. Sendo assim, com este trabalho, busco compreender como tal certificação atua como um mecanismo de "proteção" de um saber-fazer produzido em Paraty desde o século XVII, semelhante ao registro dos patrimônios imateriais.

Palavras-chave: Cachaça; Paraty; Patrimônio Cultural; Indicação de Procedência; Tradição. 


\title{
Cachaças de Paraty: Patrimonialización de una tradición
}

Resumen: La cachaça, el alcohol históricamente de Brasil, ha pasado por materiales y simbólicas transformaciones. En ese sentido, pretendo analizar las transformaciones que la cachaça producida en la ciudad de Paraty (RJ) tienen pasado, sobre todo en la última década, presentando los resultados de trabajo de campo y entrevistas semiestructuradas con los productores y trabajadores que tratan directamente con la cachaça en la ciudad. A partir de las teorías de los patrimónios culturales, parto de la suposición de que la cachaça de Paraty se caracteriza por ser un património cultural de la ciudad, a pesar de no ser oficialmente. Pues, los alambiques combinados em la "Associação de Produtores e Amigos da Cachaça de Paraty" tienen el certificado del gobierno federal de "Indicação de Procedência", que es la certificación de su "tradición" en la producción de cachaça. Siendo así, com este trabajo, trato de entender cómo este tipo de certificación actúa como un mecanismo de "protección" de un saber-hacer producido en Paraty desde el siglo XVII, similar el registro de los patrimónios intangibles.

Palabras clave: Cachaça; Paraty; Património Cultural; "Indicação de Procedência"; Tradición.

\section{Paraty's Cachaças. The patrimonialization of a tradition}

\begin{abstract}
The cachaça, alcoholic beverage historically of Brazilian origin, has passed for profound material and symbolic transformations. In this sense, I intend to analyze the transformations by which cachaças produced in the city of Paraty (RJ) have been passed, particularly in the last decade, presenting the results of field work and semi-structured interviews with producers and workers who deal directly with cachaça in the city. From the theories about the cultural heritage, I assume that the cachaças of Paraty are characterized as a cultural heritage of the city, although officially it is not. Because, the stills assembled in the "Associação de Produtores e Amigos da Cachaça de Paraty" have the certificate of the federal government of "Indicação de Procedência", which certifies to them the "tradition" in the production of cachaça. Therefore, with this paper, I seek to understand how such certification acts as a mechanism of "protection" of a know-how produced in Paraty since the seventeenth century, similar to the registration of intangible heritage.
\end{abstract}

Keywords: Cachaça; Paraty; Cultural Heritage; Statement of Source; Tradition. 


\section{Introdução}

Entre os muitos atrativos turísticos presentes na cidade de Paraty, localizada no litoral sul do estado do Rio de Janeiro, a cachaça aflora como um dos mais dinâmicos e significativos, não somente por sua importância cada vez maior para a economia da cidade, como também para a produção de sentidos do patrimônio local e regional. No entanto, a cachaça produzida em Paraty não é alvo de nenhuma solicitação de registro, o que levanta questões pertinentes tendo em vista o chamado boom dos processos de patrimonialização.

Os estudos sobre o patrimônio cultural têm passado por profundas transformações desde as últimas décadas do século XX, tornando-se tema de interesse não apenas do Estado, mas sendo incorporado aos discursos de valorização e preservação de memórias coletivas pertencentes aos diversos grupos existentes em uma nação. Nesse contexto, as políticas de proteção, conservação e preservação do patrimônio cultural tendem a seguir, progressivamente, as transformações pelas quais os grupos sociais têm passado na contemporaneidade.

Uma das noções mais relevantes do discurso que toma o patrimônio como objeto central à construção de identidades, mas também a sua reivindicação e valorização, é a noção de cultura. Categoria central do pensamento antropológico, a ideia de cultura possui uma longa história cujos ecos ainda refletem na disciplina. Reconhecendo a diversidade de manifestações, conhecimentos e de práticas, a noção antropológica de cultura revolucionou a forma como essa diversidade se contrasta com a unidade biológica da espécie humana e foi incorporada aos discursos do patrimônio pelos grupos locais ou étnicos no processo de construção e valorização de suas identidades.

Este artigo tem como proposta investigar o processo de valorização de uma suposta identidade local ou regional tomando a cachaça produzida na cidade de Paraty como valor a ser preservado, considerada uma produção coletiva, manifestação particular da cultura popular e signo presente na memória coletiva de distintos sujeitos. Compreendida como um saber-fazer local resultado de um processo de acumulação e transmissão entre diferentes gerações de conhecimentos considerados tradicionais, seu modo de fazer é analisado neste trabalho como um dos patrimônios culturais de Paraty, apesar de oficialmente não o ser.

Para tanto, este trabalho adota metodologia qualitativa, seguindo olhares hermenêutico-interpretativos, próprios da antropologia. A partir da realização de estudo de caso na cidade de Paraty, a proposta foi utilizar o trabalho de campo como um dos caminhos possíveis para a construção do conhecimento sobre o objeto deste estudo, a partir de entrevistas semiestruturadas, conversas informais e observação. Seguindo os pressupostos da antropologia interpretativa, com o auxílio de Geertz (2008), busquei realizar uma descrição 
densa, por meio da qual pude analisar as diferentes estruturas de significado acerca da cachaça encontradas em Paraty. Para transformar minhas experiências e os discursos apreendidos em campo em texto, o trabalho de James Clifford (1998) mostrou-se como essencial.

De acordo com os discursos oficiais e com os historiadores da cachaça, "Parati" é sinônimo da bebida desde o século XVII, contexto histórico no qual a cidade teria possuído mais de cento e cinquenta alambiques para sua produção. Contudo, atualmente encontramos somente seis alambiques em funcionamento, são eles: Coqueiro, Corisco, Maria Izabel, Paratiana, Pedra Branca e Engenho D’Ouro. Em 2007 as cachaças mencionadas conquistaram o registro de IP1, concedido pelo INPI2, órgão federal vinculado ao Ministério do Desenvolvimento, Indústria e Comércio, que certifica que determinada região geográfica de Paraty tem "tradição" na produção de cachaça.

A cidade possui diversas manifestações culturais que dão o tom dos inúmeros patrimônios que coloca à disposição de seus visitantes. Nesse sentido, os discursos e representações analisados neste trabalho podem ser entendidos como uma construção identitária possível em meio a diversas outras identidades possíveis, não sendo, portanto, exclusiva.

\section{Patrimônio Cultural}

Nas últimas décadas, o campo dos estudos acerca do patrimônio cultural tem passado por profundas transformações, incorporando novas categorias para se pensar a construção e a valorização de identidades a partir de elementos da cultura e da memória coletiva. É nesse contexto que surgem os chamados "patrimônios imateriais". Vale ressaltar que a formação do patrimônio cultural envolve tensões e disputas de interesses diversificados, em particular entre o Estado, os intelectuais e a sociedade civil (ABREU, 2009; ORTIZ, 2012; VELHO, 2006).

Os conflitos e as recentes transformações sobre o que seria o patrimônio cultural de um grupo ou de uma nação exigem sua problematização e encontram-se cada vez mais presentes como tema de interesse nas Ciências Sociais. Nesse sentido, iniciarei este trabalho a partir da exposição de como os patrimônios culturais são utilizados na contemporaneidade enquanto meios de representação social, estabelecendo e corroborando as fronteiras de identidades coletivas.

Acredito ser relevante analisar as formas desiguais por meio das quais os distintos grupos sociais constituem e se apropriam dos patrimônios. Sendo assim, torna-se essencial, como afirma Canclini (2008), pensar o campo do patrimônio como um espaço de luta material e simbólica entre as diferentes classes, etnias e grupos. No entanto, segundo o autor, a perenidade dos bens 
patrimoniais os tornaria uma fonte de consenso coletivo, desfazendo-se, assim, as barreiras que separam as classes, etnias e grupos.

Nessa perspectiva, uma das funções sociais do patrimônio é a de neutralizar a instabilidade social, ao passo que mantem as desigualdades sociais e a hegemonia dos grupos dominantes, responsáveis pela seleção, classificação e desfrute dos patrimônios culturais. Como explica Canclini (2008:194, grifo do autor):

[...] os bens reunidos na história por cada sociedade não pertencem realmente a todos, mesmo que formalmente pareçam ser de todos e estejam disponíveis para que todos os usem [...] diversos grupos se apropriam de formas diferentes e desiguais da herança cultural [...]. Como vimos no estudo do público em museus de arte, à medida que descemos na escala econômica e educacional, diminui a capacidade de apropriarse do capital cultural transmitido por essas instituições.

Portanto, a maneira como cada grupo tem acesso à cultura e o modo pelo qual cada um a absorve tende a ser desigual, o que possui reflexos no modo como os distintos grupos e sujeitos sociais mantêm relações com o patrimônio. Seguindo a proposta de analisar essa relação desigual a partir de olhares antropológicos, me dedicarei na seção seguinte deste trabalho a pensar como a cultura é vista a partir do senso comum, com o objetivo de tornar mais claras as implicações que essa visão assume sobre os patrimônios culturais enquanto espaços de luta material e simbólica entre grupos.

Conforme explica Abreu (2009), com a criação da Organização das Nações Unidas para a Educação, a Ciência e a Cultura (UNESCO), a concepção universalista de um patrimônio da humanidade ganha destaque. "A UNESCO representava a proposta de criação de mecanismos capazes de colocar, em relação, várias culturas nacionais" (ABREU, 2009:36). Sendo assim, o que se destaca a partir de meados do século XX é a diversidade de culturas e, respectivamente, de patrimônios, os quais começaram a ser estudados por cientistas sociais, em particular, por antropólogos.

Essas transformações, pelas quais a concepção de patrimônio passa nesse contexto, refletem as transformações do próprio conceito antropológico de cultura. Nessa perspectiva, o patrimônio cultural, gradativamente, incorpora outros valores, além dos artísticos e históricos e passa a ser entendido como "o conjunto de realizações humanas em suas mais diversas expressões. A noção de cultura incluía hábitos, costumes, tradições, crenças, enfim, um acervo de realizações materiais e imateriais" (ABREU, 2009:37).

Nesse sentido, a incorporação da noção antropológica de cultura pelo campo do patrimônio possibilitou uma ampliação do mesmo, com a inclusão de manifestações culturais para além da materialidade ou, nas palavras de Fonseca (2009), "para além da pedra e cal", como os bens imateriais ou intangíveis, tema deste trabalho. 


\section{A noção de cultura no senso comum}

A cachaça, a partir do viés do senso comum, aparece no imaginário popular vinculada à imagem negativa de seu consumo em excesso e, por sua vez, vinculada ao alcoolismo, distanciando-se de uma visão que a perceba como um elo entre o passado histórico e o presente de determinada cultura, como um elemento do cotidiano de diversos grupos. Nesse sentido, analisar os discursos e representações sociais de sujeitos particulares, os quais conferem valores e significados distintos à produção e ao consumo local da cachaça, exige problematizar, ainda que brevemente, como a cultura é concebida no senso comum e, posteriormente, através do viés antropológico.

Compreender a concepção de cultura como esta se apresenta no senso comum torna-se uma relevante tarefa de reflexão, posto que, como explica Eunice Durham (1984), esta forma de ver a cultura não está presente apenas nos outros, mas em todos nós, a partir de nossas experiências e conhecimentos vivenciados em sociedade. A noção de cultura pelo viés do senso comum, ou seja, em sua acepção popular, a coloca em uma posição de distanciamento do que está presente no cotidiano das pessoas, do que lhes é tangível, referindo-se, particularmente, às formas eruditas de representação artística, como as artes plásticas e a pintura. Sendo assim, essa noção de cultura apresenta uma clara postura elitista, como se exigisse atributos particulares para ser usufruída.

A noção elitista da cultura tende a ser muito valorizada, não somente pelos intelectuais, mas pelas pessoas em geral, pois ela incorpora valores simbólicos e seu consumo requer do apreciador um conhecimento prévio que possibilite o prazer em contemplá-la. Nas palavras de Durham (1984, p.24), “'ter cultura', portanto, no senso comum, significa possuir um certo conjunto de conhecimentos ou informações que não são utilizados no dia-a-dia das pessoas comuns e, ao mesmo tempo, ser dotado de uma capacidade especial para apreciar e usar esse patrimônio". Esta relação entre "ter cultura" ou "não ter cultura", pelo viés do senso comum, pode ser traduzida na ideia essencial de que as pessoas se dividem entre as que têm conhecimento e aquelas que não o possuem.

Portanto, "ter cultura" refere-se às produções coletivas consideradas eruditas, delimitando as fronteiras com o que seria a "cultura popular", ou "cultura de massa". Como explica Gonçalves (2008:83), nas sociedades modernas a cultura passou a ser "concebida como uma dimensão separada da experiência cotidiana das relações sociais, como um espaço nobre que abriga um conjunto de objetos passíveis de serem apropriados, contemplados, preservados e representando valores transcendentais". A cultura, nesse sentido, caracterizase por estar distante da população em geral, sendo restrita a uma classe dominante, detentora de um conjunto de conhecimentos particulares.

Porém, a cultura tende a ser valorizada por ambos os grupos, tanto pela elite, responsável pela sua seleção e classificação, como pela população que a 
admira e a respeita. Para Durham (1984) essa valorização é essencial para se pensar o processo de preservação dos bens culturais através de políticas públicas elaboradas de acordo com os interesses dos grupos envolvidos e a multiplicidade de referências associadas ao termo cultura foi fundamental para se desenvolver sua noção antropológica.

É a partir dessa concepção elitista da cultura, produzida e apreciada por determinadas classes sociais, que o viés antropológico de cultura surge, buscando sua reformulação, no sentido de "deselitizar" a cultura. Nessa abordagem, embora os aspectos associados à noção de cultura no senso comum sejam mantidos, os valores simbólicos, antes limitados ao conhecimento de determinadas classes sociais, passam a ser incorporados a todas as formas de produção humana e de comportamento social.

A dimensão simbólica dos bens materiais apresenta-se como questão norteadora da concepção de cultura e as delimitações que separam produção material e produção simbólica confundem-se ou desaparecem. O que se torna relevante destacar é que "inclusive os bens materiais mais úteis estão imersos numa espessa camada de relações sociais, elaborações estéticas e formas rituais da qual retiram muito da sua significação" (DURHAM, 1984:30). Nesse sentido, devemos analisar os usos que determinada cultura faz de suas produções coletivas, sendo seus usos os elementos fundamentais para a percepção dos seus significados. Segundo a autora, é através dos novos usos e significações conferidos ao patrimônio cultural que o trazemos de volta à vida.

Em sua pesquisa sobre os museus como espaços materiais de representação social, Gonçalves (2007:82-83) busca evidenciar a complexidade de relações sociais e simbólicas envolvidas no processo de formação e permanência dos patrimônios culturais. Apesar de abordar a dimensão material da cultura, suas reflexões acerca das relações nem sempre estáveis e harmoniosas entre diversos grupos no processo de formação do que representa suas identidades tornam-se relevantes para compreender os conflitos envolvidos nos discursos acerca do patrimônio cultural como representante de uma identidade local.

Seguindo essa perspectiva, o patrimônio imaterial caracteriza-se por sua tradição, geralmente, transmitida através da história oral e que se encontra essencialmente vinculada a um sistema de valores e significados, a partir do qual o grupo social organiza sua vida e constrói sua identidade diante de outros grupos. De acordo com o artigo $2^{\circ}$ da Convenção para a Salvaguarda do Patrimônio Cultural Imaterial, o patrimônio cultural imaterial é definido:

\footnotetext{
Pelas práticas, representações, expressões, conhecimentos e técnicas - junto com os instrumentos, objetos, artefatos e lugares culturais que lhes são associados - que as comunidades, os grupos e, em alguns casos, os indivíduos reconhecem como parte integrante de seu patrimônio cultural. Este patrimônio cultural imaterial, que se transmite de geração em geração, é constantemente recriado pelas comunidades e grupos em função de seu ambiente, de sua interação com a natureza e de sua história, gerando um sentimento de identidade e continuidade e contribuindo assim para promover o respeito à diversidade cultural e à criatividade humana (UNESCO, 2012:5).
} 
Nesta perspectiva, adotarei a concepção de patrimônio cultural imaterial definida pela UNESCO como norteadora para a abordagem do modo de fazer a cachaça artesanal de Paraty, entendido como um bem imaterial da cultura local. A partir dessa concepção, a cachaça ao ser selecionada e classificada como representante do grupo de produtores da cidade, por meio dos discursos e representações, além de refletir as ideias e valores desse grupo, também atua como "instrumento" de interações com outros grupos sociais.

Ao refletir sobre o tema do patrimônio cultural em nossa sociedade, é possível perceber que o viés do senso comum, presente na visão popular da concepção de cultura, também se encontra, por extensão, ligado a uma concepção elitista do patrimônio cultural. De acordo com esse viés, o patrimônio não está à disposição de todos os grupos sociais, apesar de a cultura ser, fundamentalmente, coletiva, produzida por todos. O acesso, o modo como cada grupo desfruta do patrimônio e como cada grupo o constrói tendem a ser diferenciados, como vimos com Canclini (2008).

O que a percepção do senso comum traz consigo, seja na noção de cultura ou de patrimônio cultural, é o estabelecimento de relações de poder entre grupos sociais dominados e dominantes. Essas relações, baseadas na apropriação de bens culturais distintos e de modos diversos, são mediadoras de construção de identidades, posto que é por meios dessas apropriações que os grupos se diferenciam entre si e, simultaneamente, expressam a imposição de gostos e padrões dos dominantes sobre os dominados

As classes dominadas, porém, por não possuírem os mesmos recursos das dominantes, constroem e mantêm suas produções coletivas de modo bem mais delicado, posto que "a produção cultural das camadas mais pobres não se arquiva e, portanto, uma vez produzida, pode ser rapidamente perdida. A memória popular é uma memória curta, exatamente porque depende da memória das pessoas", sendo uma memória preservada através da transmissão oral entre os membros do próprio grupo ou através de produções intelectuais de acadêmicos (DURHAM, 1984). No entanto, como argumenta Ortiz (2012), a memória coletiva, ou memória popular, precisa ser vivenciada no cotidiano do grupo social ao qual pertence. Nas palavras do autor:

É o grupo que celebra sua revivificação, e o mecanismo de conservação do grupo está
estritamente associado à preservação da memória. A dispersão dos atores tem
consequências drásticas e culmina no esquecimento das expressões culturais. Por
outro lado, a memória coletiva só pode existir enquanto vivência, isto é, enquanto
prática que se manifesta no cotidiano das pessoas (ORTIZ, 2012:133).

O saber-fazer e o consumo da cachaça, inicialmente restritos aos negros escravos, uma das classes dominadas nas épocas do Brasil-colônia e Brasil Império, representam uma produção coletiva carregada de significados e valores simbólicos que têm passado por profundas transformações até os dias atuais. Posteriormente apropriada pelos portugueses, por meio das técnicas de destilação já dominadas por eles, a bebida, para muitos marginalizada, ganhou espaço como um dos principais produtos econômicos do país nas épocas mencionadas, sendo seu saber transmitido entre as gerações, principalmente 
pela história oral e pela rememoração de sua produção na vida cotidiana dos sujeitos, tornando-se, nas últimas décadas, tema de interesse de pesquisas acadêmicas.

Pensar a forma como meus sujeitos pesquisados percebem a cachaça e a cultura torna-se um interessante exercício de reflexão a partir de suas relações com o patrimônio cultural de Paraty, seguindo suas visões particulares do que seja o patrimônio cultural local. Esse exercício, de dar voz aos sujeitos, encontra-se presente nos estudos acerca dos contornos que a noção de cultura possui na contemporaneidade, possibilitando sua incorporação pelo campo do patrimônio.

Os contextos culturais nos quais a cachaça está presente, enquanto elemento simbólico intermediador de relações sociais, a conferem significados os mais diversos, como resultado de distintas associações entre os elementos em cada contexto. Sendo assim, a cachaça, bebida, inicialmente, consumida pelos sujeitos à margem da sociedade, esteve em sua origem associada à uma bebida inferior, que no senso comum é compreendida negativamente como "popular". Seja pelo consumo em excesso, pelo baixo preço de muitas marcas, ou pelo grupo consumidor ao qual está associada no imaginário social, essa visão da bebida como de qualidade inferior ainda se encontra presente para muitos brasileiros.

Nas últimas décadas, no entanto, numa tentativa de realizar transformações desses significados presente na cultura popular, pesquisadores e produtores têm buscado estabelecer novas associações simbólicas, a partir do desenvolvimento tanto na qualidade da produção, como na forma como a cachaça é apresentada aos consumidores. Esse processo de revalorização da bebida, vale destacar, apresenta reflexos também no valor financeiro da mesma enquanto um produto econômico, que também se caracteriza por ser uma invenção cultural dotada de significados, o que torna o consumo de algumas de suas marcas diferenciado de acordo com cada grupo social.

Recentemente, os produtores de cachaça de Paraty têm procurado estabelecer novas associações simbólicas à cachaça como resultado dos discursos e representações comerciais que constroem destacando a ligação da bebida com um passado histórico importante para o país e para a cultura local. Nesse sentido, compreender como os produtores de cachaça de Paraty pesquisados estabelecem associações entre a cachaça e outros elementos simbólicos, me leva a refletir sobre como esse grupo social percebe a ligação entre a cachaça e a cultura local.

\section{O “estar lá" em Paraty}

O trabalho de campo realizado em Paraty, em dois momentos distintos do ano de 2015 (durante os meses de janeiro e agosto), visou compreender os significados e valores sociais conferidos à cachaça por meio dos discursos e 
representações sociais de distintos sujeitos encontrados na cidade, a saber: produtores da bebida, comerciantes locais, moradores e turistas que visitaram a cidade durante minha ida a campo. Porém, para os fins deste trabalho, neste artigo me dedicarei a apresentar e analisar os discursos e representações sociais concedidos a mim através de entrevistas formais autorizadas com os produtores e trabalhadores ligados à APACAP.

A busca foi por uma vivência em campo, ainda que breve, sem a qual não seria possível estar em contato com distintos sujeitos e suas visões de mundo sobre a cachaça. Sem a experiência em campo, comportamentos e sutilezas teriam passado despercebidos, resultando em interpretações incompletas, ainda que a plenitude de significados dificilmente seja alcançada no empreendimento antropológico. Por fim, a coleta das informações em campo ocorreu por meio de anotações, diário de campo, registro fotográfico e gravação das entrevistas.

Para os objetivos aos quais me proponho neste trabalho, o conceito de cultura defendido por Geertz apresenta-se como essencial, bem como o modo pelo qual defende que devemos realizar a prática da etnografia. Segundo o autor:

\begin{abstract}
Acreditando, como Max Weber, que o homem é um animal amarrado a teias de significados que ele mesmo teceu, assumo a cultura como sendo essas teias e a sua análise, portanto, não como uma ciência experimental em busca de leis, mas como uma ciência interpretativa, à procura do significado. É justamente uma explicação que eu procuro, ao construir expressões sociais enigmáticas na sua superfície (GEERTZ, 2008:15).
\end{abstract}

De acordo com essa perspectiva, a prática etnográfica representa um trabalho para além do "estar lá" com o "outro", como defendia Malinowski (1984), mas também "um risco elaborado para uma 'descrição densa" (GEERTZ, 2008:15). Pois não são as técnicas e os processos de pesquisa realizados em campo que definem a prática da etnografia, mas sim o esforço intelectual, a produção de conhecimento, a problematização que o pesquisador realiza sobre a sociedade na qual viveu.

A partir do exemplo das diferenças existentes entre o ato conspiratório de piscar os olhos e um caso de tique nervoso, Geertz busca esclarecer as diferentes estruturas de significados encontradas nas culturas que estudamos. Conforme o autor, o objeto da etnografia é essa "hierarquia estratificada de estruturas significantes" composta pelo que os sujeitos fazem ("descrição superficial”) e pelo que suas ações significam em sua cultura ("descrição densa”). É através dessas "estruturas superpostas de inferências e implicações que o etnógrafo tem que procurar seu caminho continuamente” (GEERTZ, 2008:17).

Nesse sentido, trabalhar com os significados atribuídos à cachaça representa um empreendimento antropológico de lidar com as interpretações dos sujeitos pesquisados, suas visões de mundo, os modos pelos quais se relacionam com outros sujeitos, construindo constantemente seus significados e valores sociais. As construções interpretativas da autora, realizadas de acordo com referenciais científicos, como explica Geertz (2008, p.25-26, grifo do autor), são interpretações de segunda e terceira mão, pois "por definição, somente um 'nativo' faz a interpretação em primeira mão: é a sua cultura”, 
constituindo-se em "ficções no sentido de que são 'algo construído', 'algo modelado’ - o sentido original de fictio - não que sejam falsas, não-fatuais ou apenas experimentos de pensamento".

\section{A “tradição" da cachaça local}

O início da produção de cachaça no Brasil confunde-se com o surgimento dos primeiros engenhos para a fabricação do açúcar na colônia, pois no final do século XV e início do XVI o açúcar era altamente valorizado pela nobreza europeia. No entanto, como explica Câmara Cascudo (2006), nas últimas décadas do século XVII, o açúcar começou a perder importância econômica para o ouro, porém a produção da aguardente de cana foi desenvolvida intensamente, apesar das taxações que sofria, principalmente, por seu papel de moeda de troca na compra de escravos.

\footnotetext{
Onde mói um engenho, destila um alambique. Alguns engenhos dispensam o açúcar. Aguardente sustenta casa e família. Parati, 1666, ao redor de Angra dos Reis, vai avançando de tal ritmo que, ao passar na centúria imediata, o nome da Vila é sinônimo nacional da aguardente. Um cálice de parati, diz-se ainda hoje, como quem diz Madeira, Porto, Colares, Cognac, Champagne, Bordeaux, Tokay, terras que são nomes de vinhos (CASCUDO, 2006:26-27, grifo do autor).
}

Segundo os discursos oficiais3, apesar de números imprecisos, no século XVIII a cidade chegou a ter, aproximadamente, 200 alambiques para a produção da cachaça. Contudo, durante os séculos XIX e XX, a cidade enfrentou uma grave crise econômica, devido ao isolamento geográfico resultado da construção do Caminho Novo, que ligava a região aurífera de Minas Gerais diretamente ao Rio de Janeiro; e como consequência da abolição da escravidão, atividade comercial através da qual a cachaça era a principal moeda de escambo. Diante desse cenário, a produção da bebida passou por uma intensa diminuição e, atualmente, a cidade possui apenas seis alambiques legalizados e ligados à Associação dos Produtores e Amigos da Cachaça de Paraty (APACAP).

Uma das particularidades da cachaça produzida em Paraty, além de o nome da cidade ser um dos sinônimos da bebida, é a certificação de Indicação Geográfica (IG) que a cachaça de Paraty conquistou em julho de 2007. A IG caracteriza-se por ser uma certificação estabelecida pela Lei número 9.279, de quatorze de maio de 1996 (Lei da Propriedade Industrial), conferida a cidades ou regiões que possuem produtos ou serviços de excepcional qualidade e/ou tradição.

A IG visa à proteção e diferenciação do que é produzido em determinadas cidades ou regiões do país por meio da delimitação geográfica da área de produção, "restringindo seu uso aos produtores da região (em geral, reunidos em entidades representativas) e onde, mantendo os padrões locais, impede que 
outras pessoas utilizem o nome da região em produtos ou serviços indevidamente" 4 .

No Brasil, a certificação da Indicação Geográfica ocorre através do registro da Indicação de Procedência (IP) ou da Denominação de Origem (DO), sendo responsabilidade do Instituto Nacional da Propriedade Industrial (INPI), órgão vinculado ao Ministério do Desenvolvimento, Indústria e Comércio, estabelecer as condições dos registros.

As cachaças de Paraty reunidas na APACAP possuem o selo de IP, que se refere ao nome do local que se tornou conhecido por produzir, extrair ou fabricar determinado produto ou prestar determinado serviço. Sendo o quarto produto brasileiro e a primeira cachaça a ser certificada pelo INPI.

Nesse sentido, a cachaça de Paraty tem sua tradição certificada por um órgão oficial do Estado nacional, conferindo novos valores simbólicos à bebida, especialmente no que tange aos contornos de uma suposta identidade paratiense. Embora a Indicação Procedência esteja direcionada a relações econômicas de mercado, ao diferenciar a cachaça de Paraty das demais, o registro desse saber fazer contribui, de certa forma, para construção do patrimônio cultural, o qual passa a representar uma identidade local, na medida em que o registro possibilita a permanência dessa prática cultural e traz benefícios a seus produtores.

Diante desse contexto, apresento os discursos dos sujeitos pesquisados, cada um ocupando uma posição determinada no jogo social, a qual não se mostra como fixa ou rígida, estabelecendo relações com a cachaça local e construindo representações sobre a bebida. A proposta é evidenciar os diferentes significados concedidos à bebida no constante processo de revalorização simbólica pelo qual ela tem passado, particularmente, nas últimas décadas, constituindo-se, assim, em um campo de disputas entre diferentes visões de mundo.

\section{Entre memórias e história}

Pensar na cachaça como signo mobilizado pelos sujeitos em Paraty me leva a pensar em como os sujeitos pesquisados conferem significados a bebida, interpretando-a de acordo com suas visões de mundo e relacionando-a às suas interpretações da história local. Nesse sentido, algumas das perguntas presentes no roteiro da entrevista giraram em torno dessa temática, como por exemplo: o que os sujeitos consideram ser patrimônio cultural da cidade e o que torna a cachaça de Paraty diferente das outras cachaças do país. Mais especificamente, com essas perguntas, busquei compreender suas interpretações do que eles mesmos entendem por patrimônio para, posteriormente, compreender se, para eles, a cachaça possui ligações com a história da cidade.

4 Informações disponíveis em: <http://www.inpi.gov.br/menu-servicos/indicacao-geografica/indicacao-geograficano-brasil >. Acesso por último em: 12 nov. 2017. 
Dentre os muitos relatos, destaco o de Maria Auxiliadora, responsável pelo Sebrae, a partir do qual pude compreender que seus pensamentos sobre o modo artesanal de fazer a cachaça vão ao encontro de algumas teorias sobre o patrimônio cultural, enquanto um saber-fazer ligado à história de grupos locais transmitido entre as gerações e que, portanto, deve ser preservado:

O Lúcio, que estava aqui, é o presidente da Associação, ele é primo da família da
Paratiana, ele quem começou, mas a família dele, seus antepassados já tinham
alambiques, a Paratiana, também. A da Coqueiro vem de uma família de mais de
cinco gerações de cachaça. A Engenho d'Ouro que começou agora, de uns dez anos
para cá. A Maria Izabel também é de família. Então, a história é muito tradicional, foi
um dos motivos que eles conseguiram a IG, porque além de ter uma cachaça de
qualidade, tem que ter tradição, tem que ter história e cultura acoplada em todo esse
processo (Maria Auxiliadora, relato oral, 2015).

Nesse sentido, o discurso de tradição histórica do saber-fazer local da cachaça é acionado em seu relato como uma das razões pelas quais as cachaças de Paraty conseguiram o selo do Instituto Nacional da Propriedade Industrial (INPI) de Indicação Geográfica (IG). Ao ligar história e cultura locais à cachaça esse relato me leva a pensar na construção de uma identificação entre Paraty e a bebida.

\begin{abstract}
A Indicação de Procedência vai mostrar que o lugar tem procedência naquela produção, na produção de cachaça, que é o que a gente tem aqui. Então, há quatrocentos anos a gente produzia, nós temos documentos que mostram os engenhos em Paraty e que a gente produzia desde aquela época. Para gente conseguir afunilar, vamos dizer assim, seria com a DO. Que mostraria que a cana de Paraty tem aquela propriedade, que o terreno de Paraty tem aquela propriedade e dessa propriedade, que só tem em Paraty, se faz a cachaça de Paraty. Nesse caso, já seria mais específico, seria a DO. A IP mostra que aqui a gente tem procedência nessa produção, que já é uma pesquisa bem complicada. Foram anos de pesquisa e tudo mais para conseguirmos comprovar. A DO já seria propriedades do local e só a cachaça de Paraty é feita daquela forma com aquelas propriedades e daquele jeito (Gabriela, relato oral, 2015).
\end{abstract}

De acordo com o relato de Gabriela, secretária da APACAP, a IP das cachaças de Paraty está vinculada a uma tradição histórica de, aproximadamente, quatro séculos, sendo sua comprovação a partir de documentos datados do período colonial brasileiro essencial para a conquista da IP. No entanto, vale destacar, que esse processo de conquista do certificado de procedência foi acompanhado por um "projeto de melhoria da qualidade da cachaça” desenvolvido e liderado, principalmente, pelo Sebrae, uma melhoria para além da materialidade, mas presente, particularmente, nos discursos de valorização simbólica da bebida.

Por sua ligação com a história e cultura local, a cachaça é apresentada, particularmente, nos discursos dos produtores e demais associados como um dos patrimônios da cidade. Porém, o fato de não existirem ações no sentido de registrar oficialmente, de patrimonializar a cachaça de Paraty, é algo que me chamou atenção durante a apreensão dos relatos. Nesse sentido, Lúcio, produtor da cachaça Pedra Branca, me forneceu um relato revelador, que tornou mais claro o possível modo de ver a questão por parte dos demais produtores e associados. Ao ser questionado se há intenção por parte de algum grupo em patrimonializar a bebida, ele me disse que: 


\begin{abstract}
Eu acho que a IG, de certa forma, protegeu já um pouco isso. Porque, a partir do momento que a gente tem uma Indicação de Procedência definida e reconhecida pelo INPI, a gente já protegeu o que é a produção da cachaça em Paraty, a forma como ela é feita e as nossas características. Isso, eu acho que a IG protegeu bem. A gente está desenvolvendo um trabalho para buscar uma DO, que é a Denominação de Origem, que já iria além da procedência, então, viria também, a parte de cultura da cana, de outros fatores que entram aí dentro. Tem algumas ações, por exemplo, a Câmara de Vereadores de Paraty, se não me engano, tinha há um tempo, um projeto de lei para nortear algumas coisas de produção da cachaça em Paraty, mas quando veio esse processo da IG com a APACAP fortalecida, regulamento de uso e tudo, eu acho que isso, meio que, se tornou desnecessário (Lúcio, relato oral, 2015).
\end{abstract}

A IP, ao "proteger" a produção de cachaça de Paraty, seu saber-fazer, confere à cidade a tradição em fazer a bebida. Essa proteção, assim como a preservação e conservação dos patrimônios culturais, como vimos, visa a estabelecer os contornos identitários entre Paraty e a cachaça, para além da delimitação geográfica de um produto comercial, de uma bebida alcoólica, mas também, como uma bebida carregada de valores simbólicos excepcionais de tradição e cultura.

\title{
Considerações Finais
}

Neste trabalho busquei analisar os discursos e representações em torno da cachaça produzida na cidade de Paraty (RJ) a partir do viés do patrimônio cultural, partindo do pressuposto de que a bebida se caracteriza como um elemento carregado de valores simbólicos ligados a história e a tradição de um saber-fazer local. Sendo assim, dediquei a primeira parte deste artigo a refletir sobre como a categoria do patrimônio cultural é utilizada na contemporaneidade enquanto um mecanismo de representação social, delimitando e reforçando as fronteiras de identidades coletivas.

Partindo de olhares antropológicos, me dediquei a analisar a relação desigual entre os grupos sociais e o patrimônio cultural a partir da visão sobre cultura presente no senso comum, tendo como proposta tornar mais claras as consequências que essa perspectiva assume sobre o patrimônio cultural enquanto espaço de luta material e simbólica. Neste sentido, analisar o desenvolvimento da noção antropológica de cultura tornou-se tarefa essencial para a compreensão do próprio desenvolvimento da noção de patrimônio cultural e suas diversidades, como os patrimônios imateriais, categoria na qual o saber-fazer da cachaça de Paraty se encaixa.

A proposta deste trabalho foi a de analisar como cada sujeito, em sua posição determinada no jogo social, mas nem por isso fixa ou rígida, estabelece relações com a cachaça, organizando seus pontos de vista e construindo representações sobre a bebida. Seguindo os pressupostos de Velho (1989), busquei trabalhar os relatos dos sujeitos a partir da construção de categorias de pensamento que surgiram durante a pesquisa teórica e nos próprios relatos, as quais foram as norteadoras para apresentação dos discursos e representações dos sujeitos pesquisados. A busca foi por evidenciar os diferentes significados 
concedidos à bebida no constante processo de revalorização simbólica pelo qual ela tem passado, particularmente, nas últimas décadas, constituindo-se, assim, em um campo de disputas entre diferentes visões de mundo.

Nesse campo de conflitos, no entanto, as posições dos sujeitos no jogo social estabelecem representações múltiplas e complementares sobre a cachaça. Sendo assim, as relações entre a bebida e os sujeitos pesquisados ganharam contornos a partir da posição que ocupam em sociedade, acionando, deste modo, categorias semelhantes para se pensar a cachaça.

A IP, ao "proteger" a produção de cachaça de Paraty, seu saber-fazer, confere à cidade a tradição em fazer a bebida. Essa proteção, semelhante ao mecanismo de salvaguarda dos patrimônios culturais, tem como objetivo a proteção comercial das cachaças de Paraty em competição no mercado. No entanto, a IP acaba por estabelecer os contornos identitários entre Paraty e a cachaça, para além da delimitação geográfica, mas também, como uma bebida carregada de valores simbólicos excepcionais de tradição e cultura, o que, nas palavras de um dos produtores entrevistados, torna sua patrimonialização "desnecessária".

Torna-se pertinente ressaltar que este trabalho não teve como um de seus objetivos garantir a certificação de autenticidade ou inautenticidade à produção de cachaça de Paraty, mas sim, analisar como essa relação conflitante é apropriada pelos discursos e pelas representações sociais dos produtores e apresentada aos demais sujeitos em suas inter-relações, delimitando e corroborando os contornos de uma identidade cultural baseada em uma tradição local.

\section{Bibliografia}

ABREU, Regina. A emergência do patrimônio genético e a nova configuração do campo do patrimônio. In: ABREU, Regina; CHAGAS, Mário (orgs.). Memória e Patrimônio. Ensaios contemporâneos. Rio de Janeiro: Lamparina, 2009.

ASSOCIAÇÃO DE PRODUTORES E AMIGOS DA CACHAÇA DE PARATY. Disponível em: <http://www.apacap.com.br/index.php >. Acesso em: 5 nov. 2017.

BRASIL, Instituto Nacional da Propriedade Industrial. Disponível em: <http://www.inpi.gov.br/>. Acesso em: 12 nov. 2017.

CÂMARA CASCUDO, Luis da. Prelúdio da Cachaça. São Paulo: Global, 2006.

CANCLINI, Néstor García. O porvir do passado. In: CANCLINI, Néstor García. Culturas Híbridas. Estratégias para entrar e sair da modernidade. 4.ed. São Paulo: Edusp, 2008.

CLIFFORD, James. A Experiência Etnográfica: antropologia e literatura no século XX. Rio de Janeiro: Editora UFRJ, 1998. 
DURHAM, Eunice Ribeiro. Texto II. In: ARANTES, Antônio Augusto (org.). Produzindo o Passado. Estratégias para a construção do patrimônio cultural. São Paulo: Brasiliense, 1984.

FONSECA, Maria Cecília Londres. Para além da Pedra e Cal: por uma concepção ampla de patrimônio cultural. In: ABREU, Regina; CHAGAS, Mário (orgs.). Memória e Patrimônio. Ensaios contemporâneos. Rio de Janeiro: Lamparina, 2009.

GEERTZ, Clifford. A Interpretação das Culturas. 1.ed. 13. reimpr. Rio de Janeiro: LTC, 2008.

GONÇALVES, José Reginaldo Santos. Antropologia dos Objetos: coleções, museus e patrimônios. Rio de Janeiro, 2007 (Museu, memória e cidadania).

MALINOWSKI, Bronislaw Kasper. Argonautas do Pacífico Ocidental. Um relato do empreendimento e da aventura dos nativos nos arquipélagos da Nova Guiné Melanésia. 3.ed. São Paulo: Abril Cultural, 1984.

ORTIZ, Renato. Cultura Brasileira e Identidade Nacional. 5. ed. São Paulo: Brasiliense, 2012.

VELHO, Gilberto. A Utopia Urbana: um estudo de antropologia social. 5. ed. Rio de Janeiro: Zahar, 1989.

Patrimônio, Negociação e Conflito. Mana, Rio de Janeiro, vol. 12, n. 1, p 237-248, 2006.

UNESCO. Textos Base. Convenção de 2003 para Salvaguarda do Patrimônio Cultural Imaterial. Paris: Unesco, 2012. 